\title{
Investigation of Nanofluids as Potential Cutting Fluids in Gear Hobbing Processes of AISI 4118 Steel
}

\author{
Hoang Vi, Ngo Minh Tuan and Tran The Long \\ Department of Manufacturing Engineering, Faculty of Mechanical Engineering, Thai Nguyen University of Technology, Thai \\ Nguyen 250000, Vietnam
}

\begin{abstract}
The present work focuses on the performance of nanofluids called CN46- $\mathrm{NanoAl}_{2} \mathrm{O}_{3} .80$ formulated by using dispersions of nano aluminum oxide $\left(\mathrm{Al}_{2} \mathrm{O}_{3}\right)$ in the ISO VG46 industrial oil on machining performance during gear hobbing of AISI 4118 steel. In machining gears, hobbing is one of the most important processes, especially to produce various gear shapes for adapting to diverse applications. However, the demand for high quality brings attention to product quality, particularly the roughness of the machined gear surface because of its effect on product appearance, function, and reliability. For additional improvement, applying nanofluids may produce superior product quality, as the rolling action of billions of nanoparticle units in the tool chip interface can significantly decrease the friction led to reduce the cutting forces. In addition, the characteristics of heat transfer of nanoparticles can contribute to reduce tool wear. In this experimental study, the performance of nanolubricant compared with the case of using ordinary cutting-fluid systems in the existing production line is investigated. The experimental results reveal that the tool life of the hob is significantly enhanced of 55.2\%, gear surface roughness is smaller (27.3\%), and gear accuracy is significantly increased by using the nanofluid. This result, therefore, shows a promising solution to achieve the engineering-economy effectiveness in gear machining.
\end{abstract}

Key words: $\mathrm{CN} 46-\mathrm{NanoAl}_{2} \mathrm{O}_{3} .80$, gear hobbing, gear surface roughness, cutting fluid, nanofluid.

\section{Introduction}

Cutting fluids are widely used by industries to reduce the friction and temperature in contact area between machine elements. There have been many studies to improve the efficiency of the cutting fluids. In recent times, nanofluid, a fluid containing nanoparticle such as $\mathrm{Al}_{2} \mathrm{O}_{3}, \mathrm{WS}_{2}, \mathrm{MoS}_{2}$, have been effectively used by their cooling lubrication for the gear transmission [1]. Compared to the general industrial lubricants, the nanolubricant can not only reduce the coefficient of friction but also increase heat transfer [2]. In the machining field [3], the recent study of nanofluid exhibits the promising results as reducing cutting temperature, improving surface finish, and decreasing tool wear. In addition, there has been a study on the effectiveness of $\mathrm{SiO}_{2}$ nanofluids in hard turning of AISI 4140 steel to reveal that the accuracy enhancement and cutting force reduction are achieved

Corresponding author: Tran The Long, Dr., research field: manufacturing engineering.
[4-6]. Owing to spherical morphology, the $\mathrm{Al}_{2} \mathrm{O}_{3}$ nanoparticles have not only the size and appropriate cost but also the mechanical and chemical properties suitable to add to the industrial oils [7]. Hence, the $\mathrm{Al}_{2} \mathrm{O}_{3}$ nano-particle lubricant can be used in cooling lubrication.

Hobbing process is one of the machining processes to manufacture different kinds of spur and helical gears. In hobbing process, gear teeth are progressively manufactured by the cuts made by a helical cutting tool called a hob. Thus, gear machining processes cause high levels of friction and wear in cutting tool and high temperature as well. These factors lead to the reduction of gear accuracy and surface finish, so using an appropriate lubricant in order to increase the tool life and the quality of the manufactured gear is very important. Using cutting fluid in subtractive manufacturing processes has various advantages, such as increasing tool life, improving surface finish, reducing temperature in cutting zone, and flushing away chips from the machining zone. Industrial 
lubricants are widely used in flood gear-hobbing processes under low levels of cutting conditions. For enhancing machining productivity as well as machining accuracy, hard machining under high levels of cutting conditions will be applied by using a hob with high precision and cost. Many types of nanoparticle have been used as a lubricant by researchers in order to investigate its effects on the machining performance. However, the application of $\mathrm{Al}_{2} \mathrm{O}_{3}$ nano material suspended in the ISO VG46 oil has not been reported in improving the gear hobbing performance of AISI 4118 steel. Therefore, this experimental study attempted to investigate the performance of $\mathrm{Al}_{2} \mathrm{O}_{3}$ as nanolubrication in gear hobbing process of AISI 4118 steel.

The experimental results reveal that the tool wear, gear profile error, and surface roughness are decreased when compared with the case of using the ISO VG46 industrial lubricant at the same cutting conditions.

\section{Experimental Design}

\subsection{Experiemental Devices}

An experimental approach to conduct the experimental research was devised to further analyze the effects of nanolubricant in gear hobbing process (Fig. 1). YBS3120 hobbing machine was used in the experiment. The hob was made from Dragon Precision Tools Co., Ltd, and its technical specification is shown in Table 1. The machined gears will be used in gear boxes of motorbikes with the number of teeth $\mathrm{Z}=21$ and the module $m=1.75$. The cutting condition is listed in Table 2, and the ISO VG46 oil mixed with $\mathrm{Al}_{2} \mathrm{O}_{3}$ nanoparticles (shown in Table 3) was used as the base cutting fluids. The machining process was carried out in Machinery Spare Parts No.1 Joint Stock Company (FUTU1), Vietnam.

\subsection{Manufacutring Method of CN46-NanoAl $\mathrm{O}_{3} .80$ Lubricant}

Depending on the existing system, the ISO VG46 industrial lubricant was widely used to gearing processes

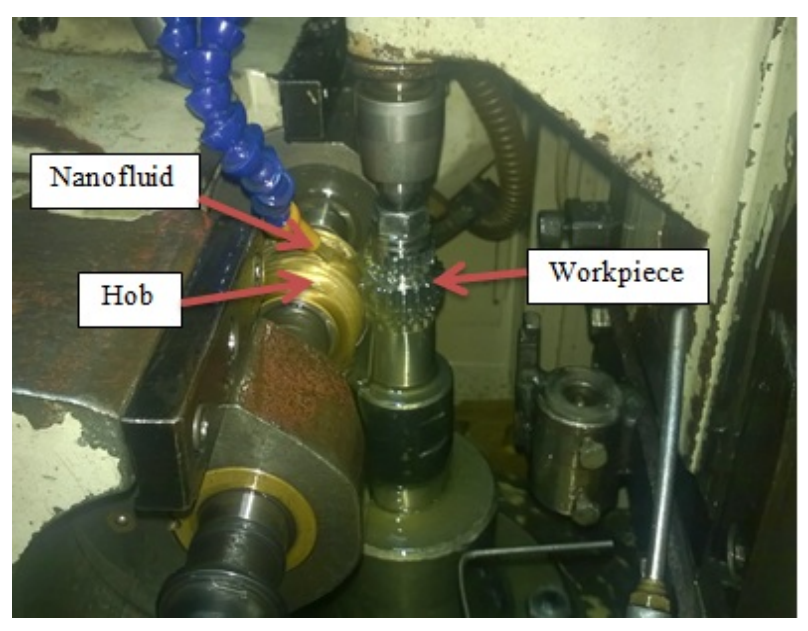

Fig. 1 Experiment setup.

Table 1 Technical specification of the hob.

\begin{tabular}{ll}
\hline Technical specification & \\
\hline Company name & DTR \\
Accuracy garde & DIN-AA \\
Module $(\mathrm{mm})$ & 1.75 \\
Outside diameter $(\mathrm{mm})$ & 60 \\
Twist angle & $1^{0} 43^{\prime}$ \\
Number of flute & 12 \\
Material & SKH-55 \\
Coated material & TIN \\
\hline
\end{tabular}

Table 2 Cutting condition.

\begin{tabular}{ll}
\hline Cutting parameter & \\
\hline Spindle speed (rev/min) & 200 \\
Depth of cut (mm) & 4.375 \\
Feed rate (mm/rev) & 1.27 \\
Milling method & Up milling \\
\hline
\end{tabular}

Table $3 \quad \mathrm{Al}_{2} \mathrm{O}_{3}$ nanoparticles specification (from US Research Nanomaterials, Inc).

\begin{tabular}{ll}
\hline Technical specification & \\
\hline Nanoparticles morphology & Nearly spherical \\
Color & White \\
Size (nm) & 80 \\
Purity (\%) & $\geq 99$ \\
Heat transfer coefficient (J/Kg.K) & $880 \mathrm{~J} / \mathrm{Kg} . \mathrm{K}$ \\
\hline
\end{tabular}

in Machinery Spare Parts No.1 Joint Stock Company due to its economical characteristics. The $\mathrm{Al}_{2} \mathrm{O}_{3}$ nanopowder made by US Research Nanomaterials, Inc is a ceramic material consisting of such many significantly physical and chemical properties as wear resistance, easy to process, and low cost. On the other hand, the $\mathrm{Al}_{2} \mathrm{O}_{3}$ nanopowder has a high sintering 
temperature, heat resistance, spherical structure and a high coefficient of heat transfer. These properties could be made the $\mathrm{Al}_{2} \mathrm{O}_{3}$ nanopowder improve the cooling and lubricating process during machining. According to Ref. [8], nanopowder was mixed with lubricant following the weight ratio of $0.1 \% / 0.2 \%$ in order to produce the nanolubricant. To compare and evaluate the cooling-lubrication effectiveness of the nanofluid, $\mathrm{Al}_{2} \mathrm{O}_{3}$ nanopowder with the size of $80 \mathrm{~nm}$ was selected according to the economical requirement. The mixing ratio is $0.1 \%$. From this, the authors call the obtained lubricant $\mathrm{CN} 46-\mathrm{Nano} \mathrm{Al}_{2} \mathrm{O}_{3} .80$. The mixing process is done by ultrasonic vibration following the procedure of Lixin Cheng [9].

\subsection{Experimental Procedure}

The machining process was carried out with the same cutting condition and hobbing tool by using the industrial lubricant ISO VG46 and the nanolubricant CN46-NanoAl $\mathrm{O}_{3} .80$.

There were two stopping times during the hobbing process. First, after the 50th gear was machined, it would also be the time of initial wear on hob. Second, after the 300th gear was machined, the tool life of hob ran out. At two stopping times, the hobbing tool and the machined gears will be measured and tested. The obtained results are used to compare and evaluate the cooling-lubrication effectiveness of each lubricant.

\subsection{Measuring and Testing Devices}

The measuring of gear profile was carried out on the OSAKA SEIKI KIKAI gear measuring machine made by Japan. The surface roughness was measured by Mitutoyo S-3000. The flank wear of hobbing tool was measured by Zeiss optical microscope (Fig. 2). The measuring processes were done in Measuring Centre in Machinery Spare Parts No.1 Joint Stock Company, Vietnam.

\section{Results}

\subsection{Evaluation of Hob Wear}

During machining process, the flank wear of the hob

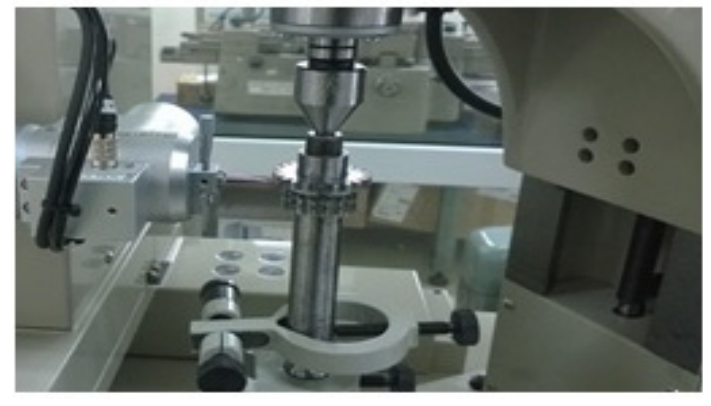

(a) gear profile error

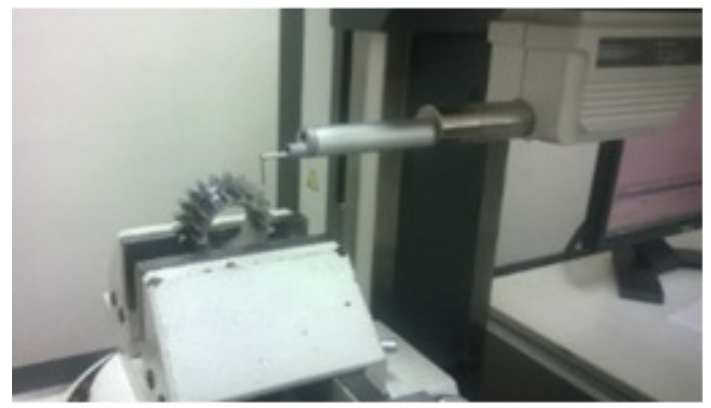

(b) gear surface roughness

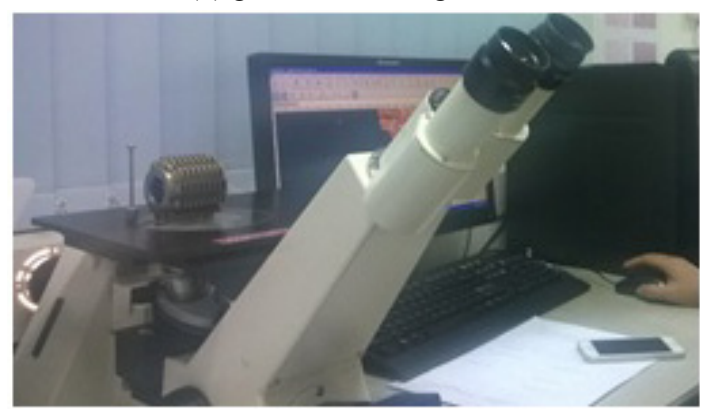

(c) flank wear

Fig. 2 Measuring processes: (a) gear profile error; (b) gear surface roughness; and (c) flank wear.

is evaluated by the width of wear land. The optical microscope and photo editing software are used for obtaining the tool wear images.

In the case of using the ISO VG46 lubricant, the widths of wear land on flank face are $36.29 \mu \mathrm{m}$ (Fig. 3a) and $89.3 \mu \mathrm{m}$ (Fig. 4a) after machining the 50th and 300th parts respectively. The widths of wear land on flank face are $24.23 \mu \mathrm{m}$ (Fig. 3b) and $39.93 \mu \mathrm{m}$ (Fig. 4b) after machining the 50th and 300th parts respectively in the case of the proposed lubricant CN46-NanoAl $\mathrm{O}_{3} .80$. Moreover, the width of wear land after machining the 360th part is only $43.56 \mu \mathrm{m}$ (Fig. 5), half time smaller than that of using the ISO VG46 lubricant after machining the 300th part. 


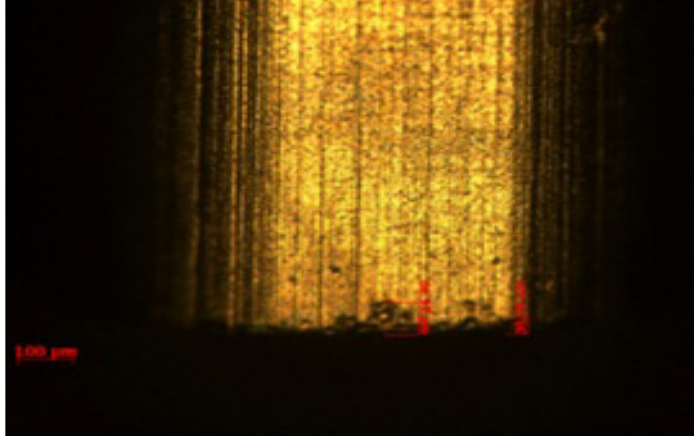

(a) $\mathrm{W}_{\mathrm{s}}=36.29 \mu \mathrm{m}$

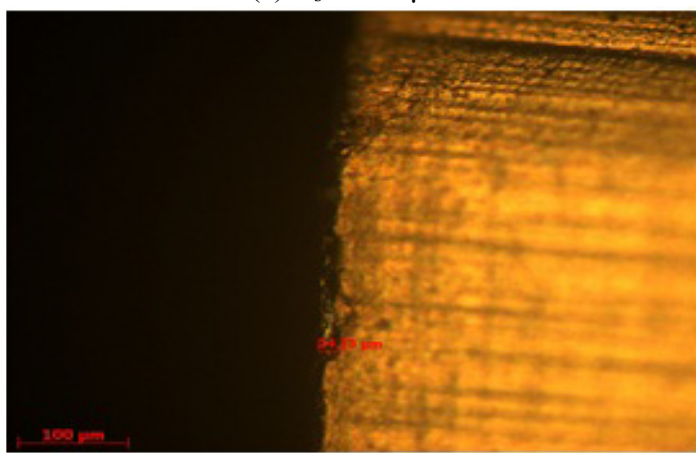

(b) $\mathrm{W}_{\mathrm{s}}=24.23 \mu \mathrm{m}$

Fig. 3 Flank wear after machining the 50th gear using: (a) ISO VG46 lubricant; and (b) $\mathrm{CN46-NanoAl} 2 \mathrm{O}_{3} .80$ lubricant.

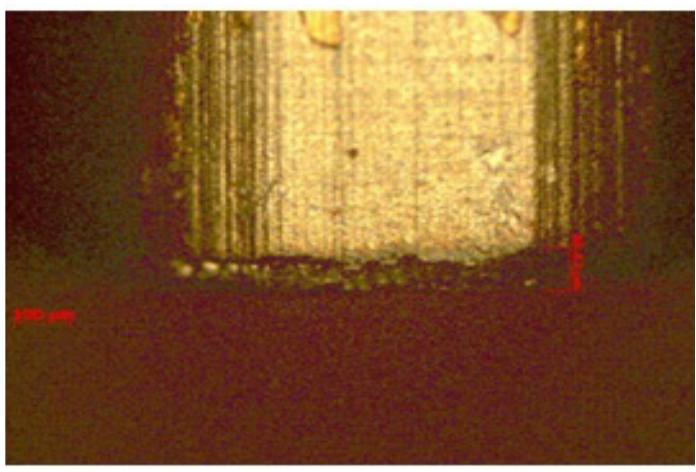

(a) $\mathrm{W}_{\mathrm{s}}=89.3 \mu \mathrm{m}$

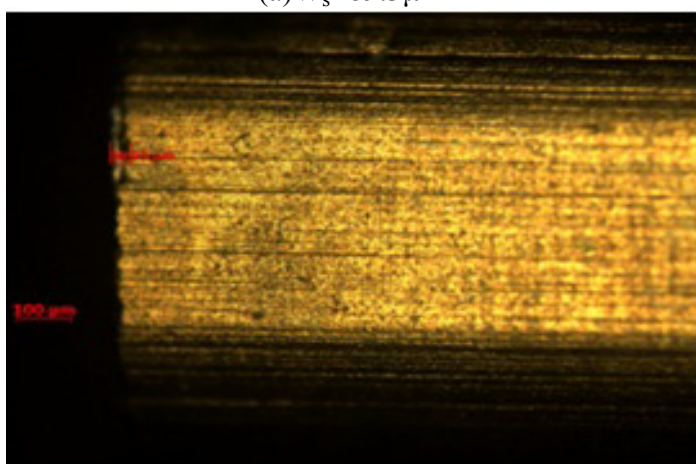

(b) $\mathrm{W}_{\mathrm{s}}=39.93 \mu \mathrm{m}$

Fig. 4 Flank wear after machining the 300th gear using:

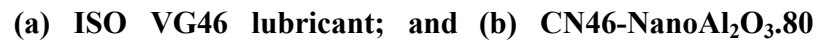
lubricant.

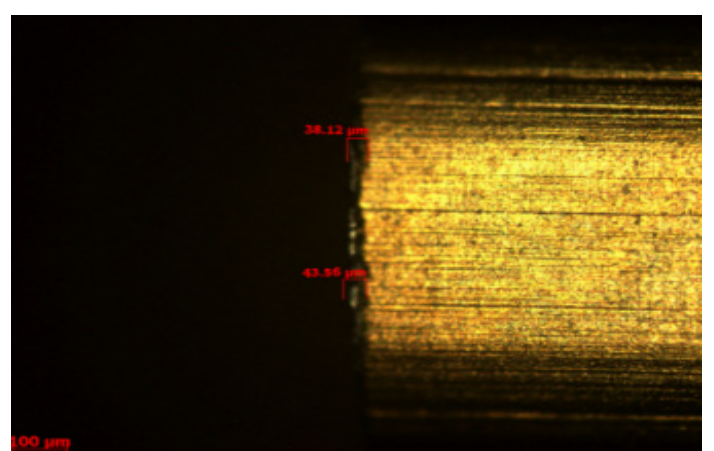

Fig. 5 Flank wear after machining the 360th gear using: CN46-NanoAl ${ }_{2} \mathrm{O}_{3} .80$ lubricant: $\mathrm{w}_{\mathrm{s}}=43.56 \mu \mathrm{m}$.

Based on that, the $\mathrm{Al}_{2} \mathrm{O}_{3}$ nanoparticles as additives in ISO VG46 base oil also effectively improve the cooling performance of the hobbing process. Nanoparticles have efficient lubrication features in addition to their satisfactory cooling performance. Therefore, the tool flank wear is much reduced and this brings out many benefits: (1) increasing hob life, (2) reducing the gear profile error, (3) improvement of gear surface smoothness and (4) reducing the friction force.

\subsection{Gear Profile Error}

Because of a generating process, there are many factors influencing the gear profile accuracy during gear hobbing, but the experiment was carried out in the same machine tool, cutting condition and hob. The only change is the ISO VG46 lubricant replaced by the proposed lubricant $\mathrm{CN} 46-\mathrm{NanoAl}_{2} \mathrm{O}_{3} .80$.

The measuring results demonstrate that the higher gear profile accuracy is achieved in the case of CN46-Nano $\mathrm{Al}_{2} \mathrm{O}_{3} .80$ lubricant (Fig. 6). The reduction of tool wear is the main factor contributed to preserve the tool profile accuracy. In addition, the spherical morphology of nano particles takes part in the decrease of friction force and cutting temperature.

\subsection{Gear Surface Roughness}

Compared to the case of using the ISO VG46 lubricant, the gear surface roughness measured in the case of using CN46-Nano $\mathrm{Al}_{2} \mathrm{O}_{3} .80$ lubricant is better. The results are shown in detail in Fig. 7. 


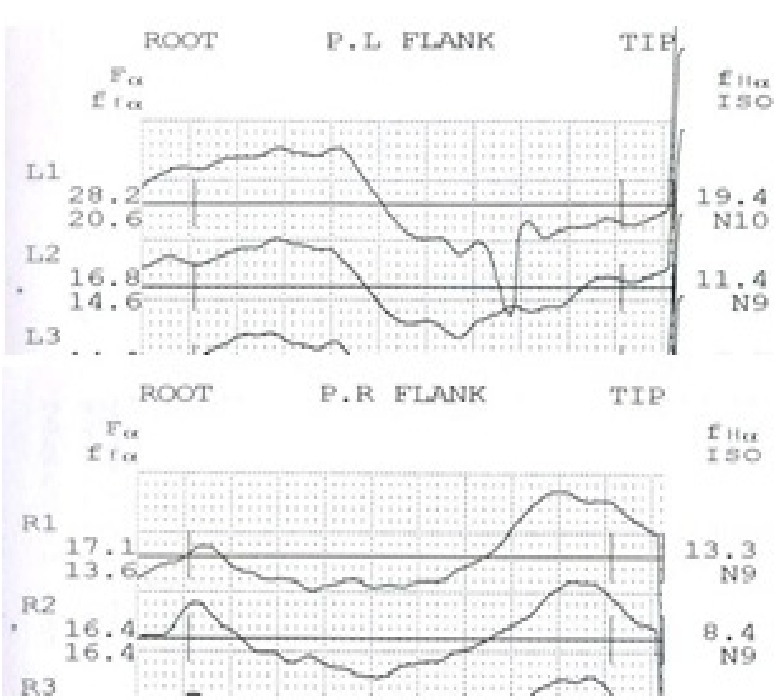

(a)

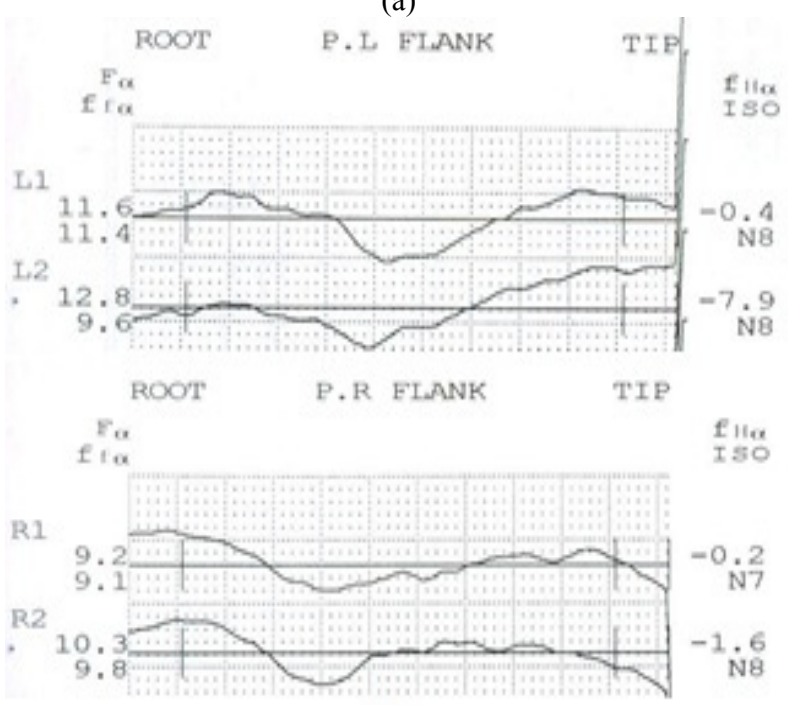

(b)

Fig. 6 Measuring the gear profile error of the 300th machined gear using: (a) ISO VG46 lubricant; and (b) CN46-NanoAl ${ }_{2} \mathrm{O}_{3} .80$ lubricant.

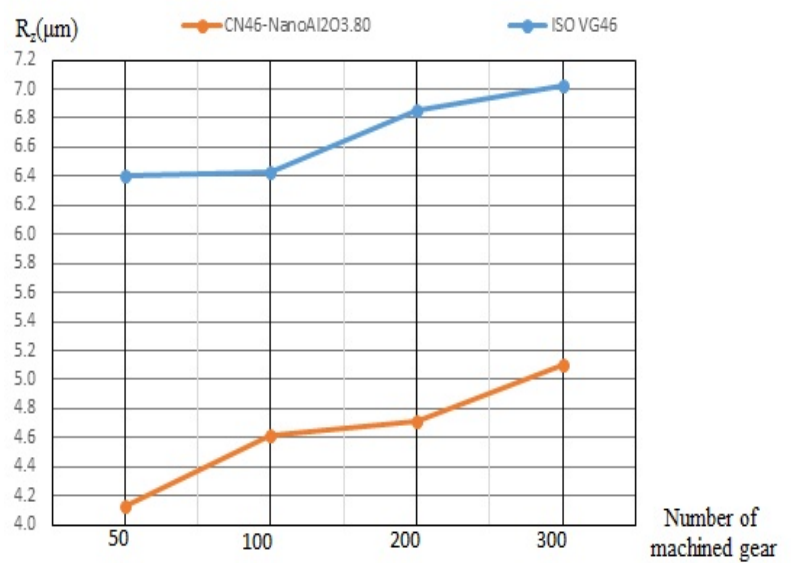

Fig. 7 The comparison of surface roughness between two types of lubricants.

\section{Conclusions}

In this investigation, the CN46-Nano $\mathrm{Al}_{2} \mathrm{O}_{3} .80$ lubricant effectively improves the cooling lubricant of the hobbing process compared to that of using the VG 46 lubricant. The $\mathrm{Al}_{2} \mathrm{O}_{3}$ nanoparticles as additives in VG 46 base oil also effectively improve the heat transfer capability and reduce the friction in cutting zone. The efficient lubrication features of nanoparticles in addition to their satisfactory cooling performance significantly lead to the decrease of hob wear, increase the tool life and enhance the gear profile accuracy and gear surface roughness. This new approach brings out not only such the promising solution for the existing gear production line but also many other applications in term of the engineering-economy effectiveness.

\section{Acknowledgment}

The authors acknowledge the device and financial support under Thai Nguyen University of Technology and Machinery Spare Parts No.1 Joint Stock Company (FUTU1), Vietnam.

\section{References}

[1] Xia, Y. Q., Wang, L., and Wang, X. B. 2007. "Application of Synthetic Lubricants in Gear Transmission." $J$ Shenyang Univ Technol 29: 484-7.

[2] Bakunin, V. N., Suslov, A. Y., Kuzmina, G. N., and Parenago, O. P. 2005. "Recent Achievements in the Synthesis and Application of Inorganic Nanoparticles as Lubricant Components." J Lubr Sci 17: 127-45.

[3] Srikant, R. R., Rao, D. N., Subrahmanyam, M. S., and Krishna, V. P. 2009. "Applicability of Cutting Fluids with Nanoparticle Inclusion as Coolants in Machining." Proc Instn Mech Engrs, Part J: J Eng Tribol 223: 221-5.

[4] Sayuti, M., Sarhan, A. A., and Salem, S. 2013. "Development of $\mathrm{SiO} 2$ Nano Lubrication System for Better Surface Quality, More Power Savings and Less Oil Consumption in Hard Turning of Hardened Steel AISI4140." Adv Mater Res 748: 56-60.

[5] Eastman, J. A., Choi, U. S., Li, S., Thompson, L. J., and Lee, S. 1997. "Enhanced Thermal Conductivity through the Development of Nanofluids." Mater Res Soc Symp Proc 457: 3-11.

[6] Wang, X. Q., and Mujumdar, A. S. 2007. "Heat Transfer Characteristics of Nanofluids: A Review." Int J Thermal Sci 46: 1-19. 
[7] Vasu, V., and Reddy, G. P. K. 2011. "Effect of Minimum Quantity Lubrication with $\mathrm{Al}_{2} \mathrm{O}_{3}$ Nanoparticles on Surface Roughness, Tool Wear and Temperature Dissipation in Machining Inconel 600 Alloy." Proc Inst MechEng $N \mathrm{~J}$ Nanoeng Nanosys 225: 3-16.
[8] Rapoport, L., Leshchinsky, V., Lvovsky, M., Lapsker, I., Volovik, Y., Feldman, Y., Popovitz-Biro, R., and Tenne, R. 2003. "Superior Tribological Properties of Powder Materials with Solid Lubricant Nanoparticles." Wear 255: 794-800. 